\title{
Correlation of Miniature Synaptic Activity and Evoked Release Probability in Cultures of Cortical Neurons
}

\author{
Oliver Prange ${ }^{1}$ and Timothy H. Murphy ${ }^{1,2}$ \\ Kinsmen Laboratory of Neurological Research, Departments of ${ }^{1}$ Psychiatry and ${ }^{2}$ Physiology, University of British \\ Columbia, Vancouver, British Columbia, V6T 1Z3, Canada
}

Spontaneous miniature synaptic activity is caused by action potential (AP)-independent release of transmitter vesicles and is regulated at the level of single synapses. In cultured cortical neurons we have used this spontaneous vesicle turnover to load the styryl dye FM1-43 into synapses with high rates of miniature synaptic activity. Automated selection procedures restricted analysis to synapses with sufficient levels of miniature activity-mediated FM1-43 uptake. After FM1-43 loading, vesicular FM1-43 release in response to AP stimulation was recorded at single synapses as a measure of release probability. We find that synapses with high rates of miniature activity possess significantly enhanced evoked release rates compared with a control population. Because the difference in release rates between the two populations is $\left[\mathrm{Ca}^{2+}\right]_{0}$-dependent, it is most likely caused by a difference in release probability. Within the subpopulation of synapses with high miniature activity, we find that the probabilities for miniature and AP-evoked release are correlated at single synaptic sites. Furthermore, the degree of miniature synaptic activity is correlated with the vesicle pool size. These findings suggest that both evoked and miniature vesicular release are regulated in parallel and that the frequency of miniature synaptic activity can be used as an indicator for evoked release efficacy.

Key words: miniature; evoked; synapse; vesicle; release; probability; pool size; calcium
Spontaneous miniature synaptic activity exists throughout the vertebrate nervous system. Miniature activity is attributed to spontaneous AP-independent presynaptic release of one (Frerking et al., 1997) or more (Vautrin and Barker, 1995; Wall and Usowicz, 1998) transmitter quanta. Findings from our laboratory using postsynaptic imaging of miniature activity indicate that the probability for miniature release is highly variant between synapses even on the same dendrite (Murphy et al., 1994, 1995; Wang et al., 1999). This variability among synapses indicates that miniature release can be regulated on the level of individual synapses. It has been shown that $\left[\mathrm{Ca}^{2+}\right]_{i}$ influences the frequency of miniature activity in CNS (Minota et al., 1991; Doze et al., 1995; Scanziani et al., 1995; Capogna et al., 1996a, 1997; Poisbeau et al., 1996; Schoppa and Westbrook, 1997; Bao et al., 1998; Li et al., 1998) and peripheral nervous system (PNS) (Matthews and Wickelgren, 1977; Marcus et al., 1992; Katz et al., 1995). Furthermore, downstream of $\mathrm{Ca}^{2+}$ influx second messenger systems such as protein kinase C (PKC) (Ghiradi et al., 1992; Parfitt and Madison, 1993; Capogna et al., 1995; Carroll et al., 1998; Stevens and Sullivan, 1998) and cAMP-dependent protein kinase A (PKA) (Chavez-Noriega and Stevens, 1994; Kondo and Marty, 1997; Chen and Regehr, 1997) have been implicated in the regulation of miniature activity. Both PKA (Ghiradi et al., 1992; Hell et al., 1995; Tong et al., 1996) and PKC (for review, see Ramakers et al.,

\footnotetext{
Received Feb. 23, 1999; revised April 21, 1999; accepted May 21, 1999.

This work was funded by an operating grant from the Medical Research Council (MRC) of Canada and the EJLB foundation. O.P. was supported by scholarships of the Deutscher Akademischer Austauschdienst (HSP-III) and the Heinrich-HertzStiftung. T.H.M. is an EJLB and MRC Scholar. We thank S. Wang and P. Mackenzie for assistance in culture preparations and for helpful comments on this manuscript.

Correspondence should be addressed to Dr. Murphy at the above address. Copyright (C) 1999 Society for Neuroscience 0270-6474/99/196427-12\$05.00/0
}

1997; Majewski and Iannazzo, 1998) have also been shown to regulate action potential (AP)-dependent transmitter release.

Unlike (AP-) evoked transmitter release (Haage et al., 1998), continued miniature release is apparently mediated by lowthreshold rather than high-threshold voltage-gated calcium channels (VGCCs) (Parfitt and Madison, 1993; Momiyama and Takahashi, 1994; Scanziani et al., 1995; Bao et al., 1998). Although different channels may control AP-evoked and spontaneous release, there is good evidence that miniature and evoked release can be regulated in parallel at presynaptic terminals of the mammalian nervous system. First, synaptic vesicles available for APevoked and AP-independent release are drawn from the same readily releasable pool (Rosenmund and Stevens, 1996). Second, both forms of release are controlled by core parts of a common release machinery (Capogna et al., 1997; Mochida et al., 1997; Hua et al., 1998). And third, changes in evoked release after the induction of short-term (Kamiya and Zucker, 1994; Cummings et al., 1996; for review, see Zucker, 1996; Fisher et al., 1997) and of long-term (Minota et al., 1991; Malgaroli and Tsien, 1992; Arancio et al., 1995; Tong et al., 1996; but see Cormier and Kelly, 1996) synaptic plasticity are paralleled by changes in miniature frequency.

These findings led us to address whether synapses that display high rates of miniature synaptic activity would also possess elevated evoked release properties. Using the styryl dye FM1-43 (Betz and Bewick, 1992, 1993), which allows monitoring of vesicular turnover at single synaptic boutons (Ryan et al., 1993, 1997; Murthy et al., 1997), we have developed a protocol to selectively load the dye into boutons with high miniature synaptic activity, as previously reported in abstract form (Prange and Murphy, 1997, 1998). We find that at synapses with high levels of miniature activity AP-evoked release is elevated. 
Figure 1. FM1-43 uptake into synaptic terminals using miniature synaptic activity and APinducing field stimulation. FM1-43 was loaded into a subpopulation of synapses with high miniature activity (white symbols) by using miniature activity-promoting conditions $\left(5 \mathrm{mM}\left[\mathrm{Ca}^{2+}\right]_{\mathrm{o}} / 0.6\right.$ $\mu \mathrm{M}$ TTX) during 10-20 min FM1-43 exposure. A control group of synapses (black symbols) was loaded with FM1-43 using AP-inducing field stimulation $(10 \mathrm{~Hz})$ during 2 min dye exposure. Both groups received respective pretreatments before dye loading to minimize differences between the individual loading protocols. After loading, for both groups ( gray symbols) identical protocols for excess dye washout (15-20 min), field stimulation $(2$ and $10 \mathrm{~Hz})$ and imaging (every $5 \mathrm{sec}$ ) were used. Synaptic FM1-43 fluorescence was recorded during an unstimulated baseline period, a period of AP-inducing field stimulation, and after complete unloading of vesicle pools using $10 \mathrm{~Hz}$ field stimulation for $2 \mathrm{~min}$. To account for the different loading protocols of both groups, evoked FM1-43 fluorescence changes were normalized to the total amount of releasable fluorescence at each synapse (see Appendix, Eq. 2). Changes in FM1-43 baseline fluorescence $(I-I I)$ and the total amount of releasable fluorescence $(I I I-V)$ were used to determine the signal-to-noise properties of each bouton. For both groups, the rate of FM1-43 fluorescence decrease (III-IV) during $2 \mathrm{~Hz}$ field stimulation was used as a measure of evoked release probability $\left(P_{\text {rel }}\right)$ at individual synapses. During periods of stimulation glutamate receptor antagonists CNQX (3 $\left.\mu \mathrm{M}\right)$ and APV (60 $\left.\mu \mathrm{M}\right)$ were present to block recurrent excitation.

\section{MATERIALS AND METHODS}

Cortical neurons and glia were dissociated from 18-d-old Wistar rat fetuses and cultured for $16-25 \mathrm{~d}$ on poly-D-lysine-coated $12 \mathrm{~mm}$ glass coverslips before experiments (as described by Mackenzie et al., 1996). For the experiments, coverslips were cut into two pieces, placed into a customized perfusion chamber $(\sim 500 \mu \mathrm{l} \mathrm{vol})$, and fixed by platinum weights to prevent movement. Continuous perfusion was supplied by an HBSS medium containing (in mM) $137 \mathrm{NaCl}, 2.5 \mathrm{CaCl}_{2}, 1.0 \mathrm{MgSO}_{4}, 5.0$ $\mathrm{KCl}, 0.34 \mathrm{Na}_{2} \mathrm{HPO}_{4}\left(7 \mathrm{H}_{2} \mathrm{O}\right), 10.0 \mathrm{Na}^{+}$-HEPES buffer, $1.0 \mathrm{NaHCO}_{3}$, and 22.0 glucose at $\mathrm{pH} 7.4$ and $\sim 315$ mOsm. $\mathrm{CaCl}_{2}$ and $\mathrm{MgSO}_{4}$ concentrations were altered as indicated in Results and in the figure legends. Additionally, the glutamate receptor antagonists D-amino-5phosphonovaleric acid (D,L-APV; $60 \mu \mathrm{M})$ and 6-cyano-7-nitroquinoxaline2,3-dione (CNQX; $3 \mu \mathrm{M})$ were added to prevent spontaneous APs and recurrent excitation during field stimulation. Constant current stimulation (30 mA; $1 \mathrm{msec}$ pulse duration) was delivered via two platinum electrodes fixed on opposite sides of the perfusion chamber (distance $\sim 8 \mathrm{~mm}$ ).

In control experiments, presynaptic terminals were loaded by applying a 1200 pulse field stimulus train at $10 \mathrm{~Hz}$ in the presence of $10 \mu \mathrm{M}$ FM1-43 (Fig. 1). FM1-43 exposure continued for $60 \mathrm{sec}$ after the stimulus train to allow for complete vesicle endocytosis (Ryan and Smith, 1995). In experiments in which FM1-43 uptake was achieved by miniature activity, the specimens were continuously exposed to $10 \mu \mathrm{M}$ FM1-43 for 10-20 min (Fig. 1). To promote miniature synaptic activity during the exposure, the medium was supplemented with $5 \mathrm{mM}\left[\mathrm{Ca}^{2+}\right], 0.6 \mu \mathrm{M}$ tetrodotoxin (TTX), and lacked $\mathrm{Mg}^{2+}$. To ensure that each treatment group received the same amount of $\mathrm{AP}$ and high $\left[\mathrm{Ca}^{2+}\right]_{0}$ stimulation, before FM1-43 loading, the miniature-loading trials were exposed to 1200 field stimuli in $2.5 \mathrm{~mm}\left[\mathrm{Ca}^{2+}\right]_{\mathrm{o}}$ and $1 \mathrm{mM}\left[\mathrm{Mg}^{2+}\right]_{\mathrm{o}}$. Accordingly, before AP-dependent loading, control trials were exposed to $5 \mathrm{~mm}$ $\left[\mathrm{Ca}^{2+}\right]_{\mathrm{o}}$ and $0.6 \mu \mathrm{M}$ TTX for $10-20 \mathrm{~min}$ (followed by a $5 \mathrm{~min}$ washout of TTX in $2.5 \mathrm{~mm}\left[\mathrm{Ca}^{2+}\right]_{\mathrm{o}}$ and $1 \mathrm{~mm}\left[\mathrm{Mg}^{2+}\right]_{\mathrm{o}}$ ). With these preloading treatments, both groups were exposed to the same solutions and stimuli before FM1-43 loading and unloading was performed (Fig. 1). This was designed to minimize differences in the protocols between miniatureloading and AP-loading (control) experiments.

For (reloading) experiments in which multiple loading and unloading trials were performed over the same area of interest (see Fig. $7 A$ ),
FM1-43 bouton loading by field stimulation was achieved using four trains of 300 stimuli $(10 \mathrm{~Hz})$ spaced by $5 \mathrm{sec}$ intervals. This protocol was expected to result in complete loading of vesicle pools. Therefore, the total amount of FM1-43 bouton fluorescence would be a measure of bouton size (Henkel et al., 1996), and the amount of evoked FM1-43 release a measure of release probability (see Appendix, Eq. 3). FM1-43 bouton loading by miniature activity was achieved by $10 \mathrm{~min}$ of continued dye exposure with $0.6 \mu \mathrm{M}$ TTX and $5 \mathrm{mM}\left[\mathrm{Ca}^{2+}\right]_{\mathrm{o}}$ present. Based on the estimated average vesicle pool sizes for cultured CNS terminals $(\sim 200$ vesicles) (Liu and Tsien, 1995; Murthy et al., 1997; Ryan et al., 1997), this protocol was expected to result in submaximal loading of vesicle pools. Hence, the amount of FM1-43 fluorescence at a synaptic bouton would be a measure of its miniature activity (probability) during the loading time (see Appendix, Eq. 4). For all experiments, preparations were washed for $15-25$ min after dye loading in the above medium supplemented with $5 \mathrm{mM} \mathrm{Mg}^{2+}$ but no added $\mathrm{Ca}^{2+}$ to minimize synaptic FM1-43 release attributed to spontaneous action potentials and miniature synaptic activity. FM1-43 bouton unloading was achieved using field stimulation protocols consisting of a $2 \mathrm{~Hz}$ stimulus train during which FM1-43 unloading was recorded, followed by a $10 \mathrm{~Hz}$ stimulus train to determine the total amount of releasable FM1-43 fluorescence (Fig. 1). All experiments were conducted at room temperature $\left(\sim 23^{\circ} \mathrm{C}\right)$.

Confocal imaging was performed on a Bio-Rad (Herts, UK) MRC 600 system attached to a Zeiss (Carl Zeiss, Oberkochen, Germany) upright microscope (Axioskop) using an Olympus 0.9 NA $60 \times$ water immersion objective (Olympus Optical, Tokyo, Japan). Laser intensity was attenuated to $1 \%$ for imaging experiments. The confocal pinhole was set to 4.5 (Bio-Rad units) for reloading experiments and to 3.0 for all other experiments. To improve signal-to-noise properties, the confocal slow scan mode (without averaging) was used. For data acquisition, a field of $128 \times 128 \mu \mathrm{m}(400 \times 400$ pixels $)$ was scanned every $5 \mathrm{sec}$ during baseline and periods of field stimulation (Fig. 1). Image collection during the baseline period was used to calculate the signal-to-noise ratio at each synapse and was followed by $15 \mathrm{sec}$ of $2 \mathrm{~Hz}$ field stimulation to determine the fractional FM1-43 unloading (Fig. 1, see Fig. 5; see Appendix, Eqs. 1,2). For experiments in which absolute (rather then fractional) FM1-43 fluorescence changes were evaluated (see Figs. 4, 7-9), corrections were made for uneven illumination (lower signal at edges of field) by dividing all fluorescence by a control image of a carboxyfluorescein solution. 

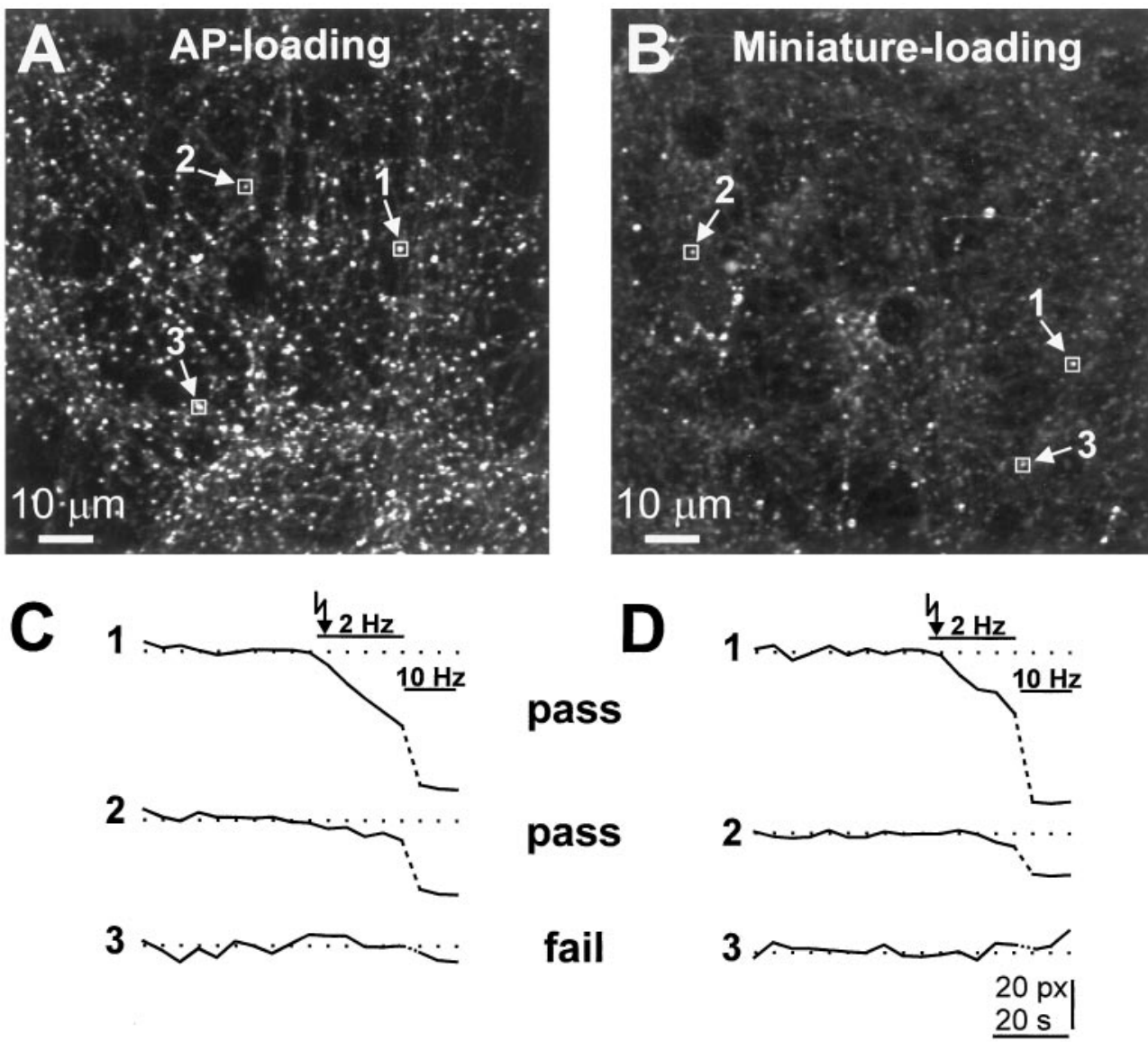

Figure 2. Automated procedure to select responsive from nonresponsive putative synaptic sites. $A, B$, Confocal image showing punctate FM1-43 staining pattern in cultured cortical neurons after $(A)$ delivery of 1200 field stimuli with dye present (controls) or $(B)$ incubation in miniature synaptic activity-promoting medium for $15 \mathrm{~min}$ with dye present. For both FM1-43-loading protocols excessive background dye was washed out for 15-20 min. Under conditions that promote miniature synaptic activity only a subpopulation $(\sim 20 \%)$ of all boutons load a significant amount (see Materials and Methods) of FM1-43 into a pool releasable by APs. Boxes 1-3 refer to putative synaptic boutons that were subjected to an automated criterion selecting responsive from nonresponsive putative boutons $(C, D) . C, D$, Plot of FM1-43 fluorescence versus time at putative synaptic boutons highlighted in $A$ and $B$, respectively. Confocal images were taken every $5 \mathrm{sec}$ during $45 \mathrm{sec}$ of baseline and $15 \mathrm{sec}$ of $2 \mathrm{~Hz}$ field stimulation. Residual FM1-43 fluorescence remaining after a 1200-pulse stimulus train $(10 \mathrm{~Hz})$ was subtracted at each site to determine the total amount of releasable dye. To be selected for further analysis, putative synapses have to pass the following automated criteria (see Materials and Methods): (1) total amount of releasable dye has to be $>0$; (2) variation (SD) of baseline fluorescence has to be $<10 \%$ of total amount of releasable fluorescence. Putative synaptic boutons 1 and 2 pass, and 3 fails the criterion. Lightning bolt depicts onset of AP-inducing field stimulation.

Additionally, in these experiments a (vertical) Z-series of 13 consecutive confocal images (spaced at $0.54 \mu \mathrm{m}$ ) over the area of interest was acquired after each loading trial utilizing a computer controlled focus motor. The fluorescence intensity of each bouton in the focal plane was corrected based on its relative position within the confocal Z-series (Prange and Murphy, 1999). Furthermore, boutons contaminated by signals from stained structures above or below their focal plane were eliminated from further analysis (Prange and Murphy, 1999).

Confocal images were exported as byte data and analyzed using customized routines written in IDL (Research Systems, Inc., Boulder, CO). For each experiment, 100-400 putative synaptic boutons were analyzed, and fluorescence changes over time were averaged over $\sim 2.6$ $\mu \mathrm{m}^{2}$ at each site. Putative boutons were randomly selected based on averaged images acquired during the unstimulated baseline period. For experiments that determined the number of responsive boutons within the visual field (Fig. 3C,D), the selection of responsive boutons was maximized by using a difference image that depicted the loci of FM1-43 release during field stimulation.

Nonreleasable fluorescence (i.e., fluorescence remaining after the 1200 pulse field stimulus train) was subtracted at each bouton before further analyses were performed. FM1-43 changes were averaged over $15 \mathrm{sec}$ of a $2 \mathrm{~Hz}$ stimulus train (three images) and during an identical time interval of nonstimulated baseline (Fig. 1). For (reloading) experiments using multiple loading and unloading trials (see Figs. 7-9) and experiments comparing absolute amounts of FM1-43 uptake (Figs. 3D, 4), raw FM1-43 fluorescence $(\Delta F)$ changes were analyzed (see Appendix, Eq. 3). For all other experiments, FM1-43 fluorescence changes were normalized to the total amount of releasable FM1-43 fluorescence $(\Delta F / F)$ (see Appendix, Eq. 1). An automated response criterion was used to select responsive from nonresponsive putative boutons (Fig. 2). To be considered for further analysis, boutons had to meet the following criteria: (1) there must be a net decrease in FM1-43 fluorescence in response to a 2 and a $10 \mathrm{~Hz}$ train of field stimuli; and (2) the SD of the baseline had to be $<10 \%$ of the total releasable fluorescence of the bouton. The criteria were modified for reloading experiments as follows: (1) the total releasable fluorescence of the boutons after loading by miniature activity had to be $>5 \times \mathrm{SD}$ of the baseline fluorescence; and (2) the decrease in FM1-43 fluorescence during 40 stimuli at $2 \mathrm{~Hz}$ had to $>2.0 \times \mathrm{SD}$ of the baseline fluorescence. Additionally, in these experiments analysis was restricted to boutons at which the amount of FM1-43 uptake during 1200 AP stimulation exceeded the amount of FM1-43 uptake during $10 \mathrm{~min}$ incubation time in a miniature activity-promoting medium ( $80 \%$ of all sites selected). This was done to ensure that FM1-43 loading using 1200 APs resulted in a fluorescence measurement representative of the entire vesicle pool.

Whole-cell patch clamping (Hamill et al., 1981) was conducted using an Axon Instruments (Foster City, CA) Axopatch 200B amplifier and 7 $\mathrm{M} \Omega$ electrodes pulled from $1.5 \mathrm{~mm}$ glass capillaries. The patch pipettes were filled with a solution containing (in $\mathrm{mM}$ ): $122 \mathrm{~K}^{+} \mathrm{MeSO}_{4}, 20 \mathrm{NaCl}$, $5 \mathrm{Mg}^{2+}$-ATP, $0.3 \mathrm{GTP}$, and 10 HEPES, 200-300 $\mu \mathrm{M}$ Fluo-3 $\mathrm{K}^{+}$salt, $\mathrm{pH}$ 7.2. Voltage-clamp recordings had APV $(60 \mu \mathrm{M})$ present in the extracellular medium to isolate the AMPA-mediated current of the postsynaptic EPSCs.

For statistical testing of normality, the Kolmogorov-Smirnov test was used. For comparison of the means of normally distributed distributions, the unpaired and paired $t$ test was used as indicated. The medians of non-Gaussian distributions were compared using the nonparametric Mann-Whitney $U$ test. For correlation analysis, the nonparametric Spearman test was used over the Pearson test when it resulted in a better fit to a linear model.

\section{RESULTS}

\section{Selective FM1-43 loading of synapses with APs and with high rates of miniature synaptic activity}

Using field electrical stimulation and confocal microscopy, we have been able to image loading and release of the styryl dye 
Figure 3. Elevated miniature synaptic activity in the presence of high $\left[\mathrm{Ca}^{2+}\right]_{\mathrm{o}}$. $A$, Whole-cell voltage-clamp recordings were performed to measure the effect of $\left[\mathrm{Ca}^{2+}\right]_{\mathrm{o}}$ on the rate of miniature synaptic activity. Examples of voltageclamp records from one cell. The cell was perfused with the indicated extracellular divalent ion concentrations (in $\mathrm{mm})$ : $0.6 \mu \mathrm{M}$ TTX was added to block spontaneous APs. B, Plot of the ratio of miniature activity (events per second) in high versus low $\left[\mathrm{Ca}^{2+}\right]_{\mathrm{o}}$ from $(n=5)$ cells. Miniature activity is significantly elevated in all cells during multiple trials of $\left[\mathrm{Ca}^{2+}\right]_{0}$ wash-in $(* * * p<0.0001)$. Error bar indicates SEM ratio across cells. $C$, Percentage of synapses loaded FM1-43 by miniature synaptic activity as a function of $\left[\mathrm{Ca}^{2+}\right]_{\mathrm{o}}$. Synapses of sister cultures were perfused with either a high or low $\left[\mathrm{Ca}^{2+}\right]_{0}$ containing medium during $13 \mathrm{~min}$ of dye exposure $(n=14$ experiments). An automated criterion was applied to select boutons that showed significant FM1-43 uptake during the different treatments periods. The average percentage of boutons that load FM1-43 into their releasable vesicle pools by miniature activity significantly increases (by $\left.4.9 \times ;{ }^{*} p<0.05\right)$ when elevating $\left[\mathrm{Ca}^{2+}\right]_{0}$ from 0 to $5 \mathrm{~mm}$. $D$, The average amount of miniature activity-mediated FM1-43 uptake does not differ between the groups. Ion concentrations are millimolar. Error bars indicate SEM.

FM1-43 from presynaptic boutons of cultured cortical neurons. For FM1-43 uptake into vesicle pools of synaptic boutons (bouton loading), two different protocols were used. The first protocol consisted of a large number of AP-inducing field stimuli (1200 pulses at $10 \mathrm{~Hz}$ ) in the presence of FM1-43 with continued dye exposure for $60 \mathrm{sec}$ after stimulation to allow complete endocytosis (Ryan and Smith, 1995) (Fig. 1). This protocol is expected to result in loading of all synaptic sites within the electrical field independent of their degree of miniature activity, which occurs at much lower rates (Murphy et al., 1995; Stevens and Sullivan, 1998; Wang et al., 1999). Previously, we had confirmed that each field stimulus reliably elicits a single AP when recurrent excitation was blocked by a combination of glutamate receptor antagonists APV and CNQX (Prange and Murphy, 1999).

The second protocol for FM1-43 bouton loading used conditions that facilitated spontaneous miniature synaptic activity by elevating $\left[\mathrm{Ca}^{2+}\right]_{\mathrm{o}}$ to $5 \mathrm{~mm}$ (no added $\left[\mathrm{Mg}^{2+}\right]_{\mathrm{o}}$ ) and suppressed AP-dependent activity using $0.6 \mu \mathrm{M}$ TTX (Fig. 1). Findings from our laboratory indicate that most synapses within a neuron have low rates of miniature activity $(\leq 0.01 \mathrm{~Hz})$, but a subpopulation of synapses exhibits high rates $(\geq 0.1 \mathrm{~Hz})$ (Wang et al., 1999). Based on these rates we chose FM1-43 exposure times of 10-20 min (in $5 \mathrm{~mm}\left[\mathrm{Ca}^{2+}\right]_{\mathrm{o}} 0.6 \mu \mathrm{M}$ TTX) to preferentially load the dye into synapses with high levels of miniature activity. Using these conditions, we were able to use miniature synaptic activity to load FM1-43 into a vesicle pool that was releasable by APs (Fig. $2 B, D)$. We confirmed that miniature synaptic activity was enhanced under these conditions by using whole-cell patch-clamp recordings ( $n=5$ neurons). These experiments demonstrated that the frequency of miniature activity was significantly increased (on average, $9.0 \pm 5.4$-fold; $p<0.05$, paired $t$ test) when $\left[\mathrm{Ca}^{2+}\right]_{\mathrm{o}}$ was elevated from 0 to $5 \mathrm{~mm}$ and $\left[\mathrm{Mg}^{2+}\right]_{\mathrm{o}}$ was decreased in parallel from 5 to $0 \mathrm{~mm}$ (Fig. $3 A, B)$. In additional $(n=14)$ experiments, we compared the extent of synaptic FM1-43 loading during 13 min dye exposure under conditions expected to elevate miniature synaptic activity $\left(5 \mathrm{~mm}\left[\mathrm{Ca}^{2+}\right]_{\mathrm{o}}, 0.6 \mu \mathrm{M}\right.$ TTX, no added $\left.\left[\mathrm{Mg}^{2+}\right]_{\mathrm{o}}\right)$ and suppress it $\left(5 \mathrm{~mm}\left[\mathrm{Mg}^{2+}\right]_{\mathrm{o}}\right.$, no added $\left.\left[\mathrm{Ca}^{2+}\right]_{\mathrm{o}}\right)$, respectively. An automated procedure was used to quantitatively select FM1-43-stained boutons from nonspecific background staining (see Materials and Methods). We found a significant difference in the number of boutons that loaded FM1-43 into their vesicle pools by miniature synaptic activity when comparing sister cultures exposed to high versus low $\left[\mathrm{Ca}^{2+}\right]_{0}$ during FM1-43 presence. Of all putative sites tested $7.0 \%(n=49$ of 700$)$ loaded in $5 \mathrm{~mm}\left[\mathrm{Ca}^{2+}\right]_{\mathrm{o}} / 0.6 \mu \mathrm{M}$ TTX, but only in $1.4 \%(n=10$ of 700$)$ loaded in the $\mathrm{Ca}^{2+}$-free $5 \mathrm{~mm}$ $\left[\mathrm{Mg}^{2+}\right]_{\mathrm{o}}$ solution $(p<0.05$, unpaired $t$ test) (Fig. 3C). However, the average amount of FM1-43 uptake into boutons was not different under the different loading conditions (high $\left[\mathrm{Ca}^{2+}\right]_{0}{ }^{-}$ loading: $23.4 \pm 10.5$ pixel value; low $\left[\mathrm{Ca}^{2+}\right]_{\mathrm{o}}$-loading: $27.3 \pm 15.8$ pixel value; $p>0.10$, unpaired $t$ test) (Fig. $3 D$ ). Taken together, these findings indicated that, while miniature activity persists at relatively high levels at a very small number of synapses in an apparently $\left[\mathrm{Ca}^{2+}\right]_{\mathrm{o}}$-independent manner, the elevation of $\left[\mathrm{Ca}^{2+}\right]_{\mathrm{o}}$ greatly facilitates the total number of synapses that reach these high levels of miniature activity.

Next, in $(n=17)$ experiments we compared the amounts of synaptic FM1-43 uptake between boutons loaded by miniature synaptic activity during 10 min versus boutons loaded by 1200 AP-inducing field stimuli (controls). To accurately measure synaptic FM1-43 in both groups, identical imaging settings were used, and out-of-focus correction for the FM1-43 fluorescence of each bouton was used (see Materials and Methods). We found that synaptic FM1-43 uptake during 1200 field stimuli (eight experiments; $n=822$ boutons) exceeded the FM1-43 uptake during $10 \mathrm{~min}$ of miniature activity (nine experiments; $n=335$ 


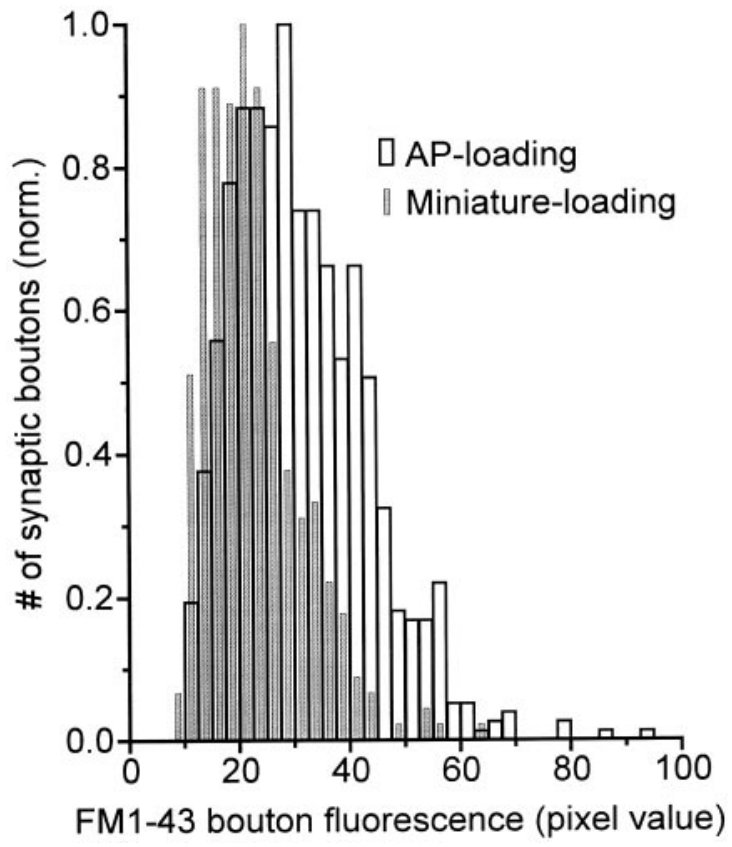

Figure 4. Submaximal FM1-43 loading of vesicle pools during 10 min of miniature synaptic activity. The amount of synaptic FM1-43 loading was compared between two groups of synapses subjected to different loading conditions. In the first group ( gray bars; $n=335$ boutons), FM1-43 uptake was achieved by $10 \mathrm{~min}$ of dye exposure in a miniature activitypromoting medium $\left(5 \mathrm{mM} \mathrm{Ca}^{2+} / 0.6 \mu \mathrm{M}\right.$ TTX). In the second (control) group (white bars; $n=822$ boutons) FM1-43 uptake was stimulated by 1200 AP-inducing field stimuli. Responsive boutons were selected by an automated criterion (Fig. 2). Distributions of the FM1-43 uptake amounts in the two groups indicate that AP stimulation results on average in $40 \%$ more synaptic FM1-43 uptake than miniature activity during 10 min. For comparison, each histogram is scaled to its maximal bin value (bin size $=2.5$ pixel value) .

boutons) significantly by an average of $40 \%$ ( $p<0.0001$, MannWhitney $U$ test) (Fig. 4). These results indicated that miniature activity during $10 \mathrm{~min}$ results in detectable, yet submaximal FM1-43 uptake into vesicle pools of a subpopulation of synaptic boutons.

After FM1-43 loading and excess dye washout (Fig. 1; see Materials and Methods), we could show that FM1-43 fluorescence was associated with the loading of synaptic vesicle pools by eliciting dye unloading with AP-inducing field stimulation (Fig. 2). Because of the lipophilic nature of FM1-43 (Betz et al., 1996) it is possible to have background staining, even after extensive dye washout. Hence, we developed an automated procedure to identify synaptic terminals based on their individual signal-tonoise ratio and their FM1-43 unloading response after field stimulation (Fig. 2). This automated procedure selected putative boutons (i.e., punctate FM1-43 spots of $<2.6 \mu \mathrm{m}^{2}$ ) for further analysis only if they showed a net reduction in fluorescence during field stimulation and if their baseline variance was low relative to the amount of release (Fig. 2C,D; see Materials and Methods). Using this procedure, we were able to sort responding from nonresponding putative boutons. Furthermore, it allowed us to select a group of boutons with "high miniature activity" based on their degree of FM1-43 loading. We are aware that the binary distinction created by the criterion does not necessarily reflect a biological threshold. However, it made it possible to analyze the data with a minimized impact of observer bias. For (control) experiments in which FM1-43 loading was achieved by field stimulation, we found that $62 \%(n=2439$ of 3920$)$ of small punctate FM1-43 staining structures exhibited significant unloading in response to a $10 \mathrm{~Hz}$ stimulus train, and therefore were likely to be synaptic boutons. In contrast, for experiments that used miniature synaptic activity (and not APs) to load FM1-43, only $14 \%$ of putative synaptic boutons $(n=1617$ of 11050$)$ were selected by the automated criteria. These results indicate that only a subpopulation of $23 \%(14 \% \div 62 \%)$ of synaptic boutons exhibit sufficient miniature activity during 10-20 min to load a significant amount of FM1-43 into their vesicle pools that is releasable by APs (Fig. 2, compare $A, B$ ). Although this procedure did not give us a quantitative measure of vesicular turnover caused by miniature activity, it provided us with a method to select a subpopulation of CNS terminals based on their degree of miniature synaptic activity.

\section{Comparison of release rates between synapses with} high miniature activity and a control population

After establishing conditions under which we could reliably load FM1-43 into synaptic boutons with miniature activity, our aim was to compare the release probability $\left(P_{\text {rel }}\right)$ at sites loaded by miniature activity versus (control) sites loaded by AP stimulation. To estimate the $P_{\text {rel }}$ at synapses of both groups (see Appendix, Eqs. 1, 2), the initial rate of FM1-43 fluorescence release during $15 \mathrm{sec}$ of a low-frequency $(2 \mathrm{~Hz})$ stimulus train (in $2.5 \mathrm{~mm}$ $\left[\mathrm{Ca}^{2+}\right]_{\mathrm{o}}, 1.0 \mathrm{~mm}\left[\mathrm{Mg}^{2+}\right]_{\mathrm{o}}$ ) was determined (Fig. $5 A, B$ ). Over this time period, we observed a linear decrease in FM1-43 fluorescence in both groups (linear regression; $r=-1.0 ; p<0.0001$ ), indicating that little depression occurred (Fig. $5 B$ ). To determine whether differences in FM1-43 release rates between boutons were attributed to nonspecific dye loss, we analyzed FM1-43 fluorescence changes during a baseline period identical in length (15 sec) to that one used for calculation of AP-evoked FM1-43 release (Fig. 1; see Materials and Methods). We found unspecific FM1-43 fluorescence decrease during a $15 \mathrm{sec}$ baseline period to be relatively small $(0.16 \%$ for miniature loaded synapses; $0.55 \%$ for AP-loaded controls) compared with the decrease observed during $15 \mathrm{sec}$ of $2 \mathrm{~Hz}$ field stimulation (12.1\% for miniature loaded synapses; $9.8 \%$ for AP-loaded controls). Moreover, as our analysis showed no positive correlation between FM1-43 baseline changes and evoked release (correlation coefficient $r=-0.18$ for miniature-loaded synapses; $r=-0.18$ for AP-loaded synapses), evoked release rates were not corrected for baseline variation.

Absolute amounts of FM1-43 release from vesicle pools depend on the degree of vesicle pool loading (see Appendix, Eq. 2). As vesicle pool loading was expected to differ between the different loading protocols (Fig. 4), we normalized stimulus-evoked FM1-43 fluorescence changes $(\Delta F)$ to baseline fluorescence $(\mathrm{F})$ for each bouton (Fig. 5A,B) (see Appendix, Eq. 2). Using the initial normalized rate of release $(\Delta F / F$ during $15 \mathrm{sec}$ of $2 \mathrm{~Hz}$ field stimulation), we were able to pool data from a large number of experiments ( $n=22$ miniature-loaded; $n=19$ AP-loaded) in each group. Comparison of the AP-evoked release rates between miniature-loaded and AP-loaded synapses showed that $(n=842)$ synapses with high levels of miniature activity released significantly more FM1-43 per stimulus than $(n=1014)$ control sites loaded by APs (24\% difference; $p<0.0001$ ) (Fig. 5C).

\section{Calcium dependency of enhanced release rates at} synapses with high levels of miniature synaptic activity

Because our data suggested that synapses with high miniature synaptic activity release more FM1-43 per stimulus than control 


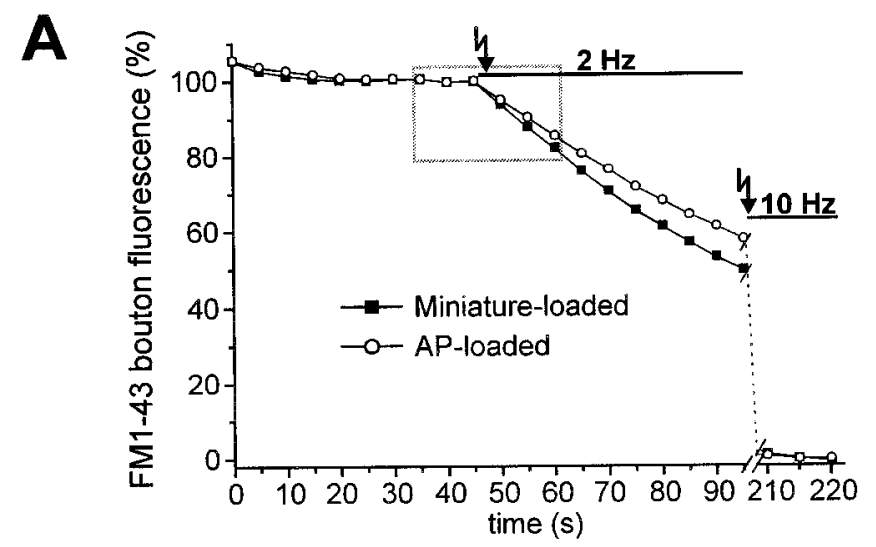

B

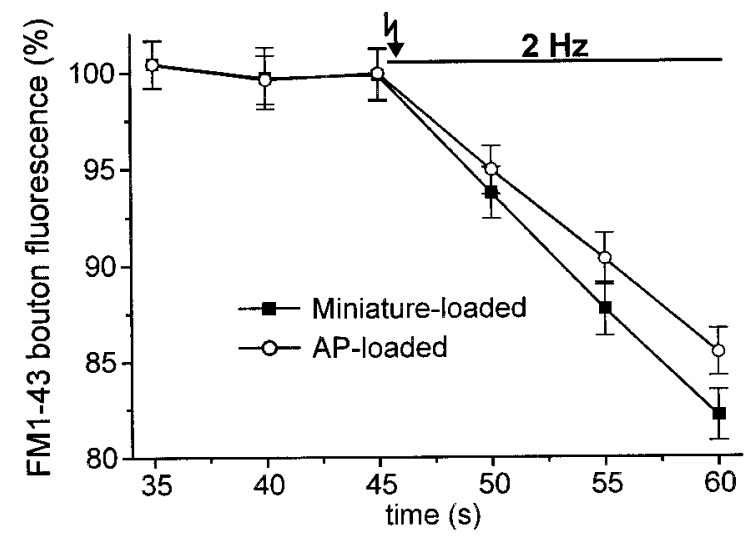

C

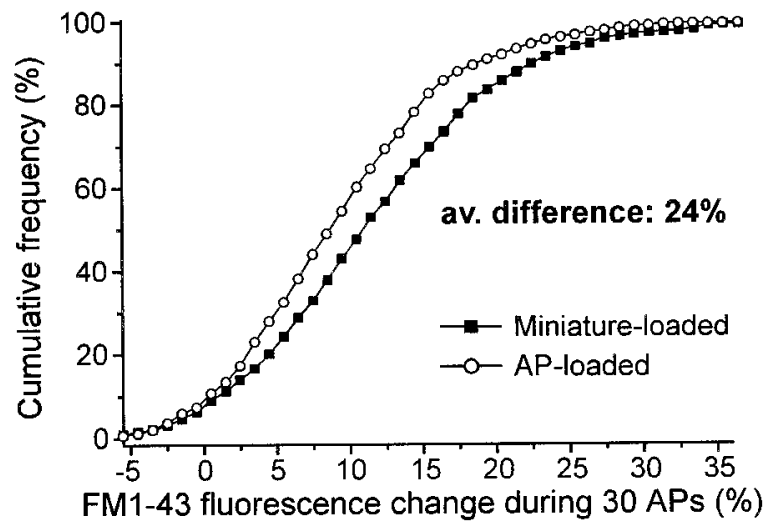

Figure 5. Synapses with high miniature synaptic activity show significantly enhanced AP-dependent vesicular release. A, AP-evoked FM1-43 release was monitored at two groups of synaptic boutons loaded by distinct protocols. Average FM1-43 bouton fluorescence versus time for $(n=842)$ synapses loaded under miniature activity-promoting conditions (Miniature-loaded $)$ and $(n=1014)$ control synapses loaded by APs $(A P$ loaded). Boutons were unloaded by a 2 and $10 \mathrm{~Hz}$ AP-producing stimulus protocol in $2.5 \mathrm{mM}\left[\mathrm{Ca}^{2+}\right]_{\mathrm{o}}$ (Fig. 1). Background fluorescence remaining after a $10 \mathrm{~Hz}$ AP train (1200 stimuli) was subtracted from each bouton, and bouton fluorescence was normalized to FM1-43 loading (average baseline fluorescence between 35-45 sec). Lightning bolt depicts onset of AP-inducing electrical field stimulation. $B$, Magnification of FM1-43 fluorescence traces in boxed region from $A$. AP-evoked FM1-43 release at each synapse during 30 APs was calculated by averaging data points from 50-60 sec and subtracting this value from the FM1-43 loading (100\%). Error bars indicate SEM. C, Cumulative frequency plot shows that evoked FM1-43 release is shifted toward higher release values at miniatureloaded sites as compared with AP-loaded controls. synapses, we further characterized this relationship under conditions expected to change release probability. Therefore, $\left[\mathrm{Ca}^{2+}\right]_{\mathrm{o}}$ was altered to 1.0 and $5.0 \mathrm{~mm}$ to either reduce or increase release probability $\left(P_{\text {rel }}\right)$, respectively. In these experiments (as for the experiments in $2.5\left[\mathrm{Ca}^{2+}\right]_{\mathrm{o}}$ ) FM1-43 baseline fluorescence variation did not contribute significantly to the rates of FM1-43 release during stimulation. As expected, we found that decreasing $\left[\mathrm{Ca}^{2+}\right]_{\mathrm{o}}$ from 2.5 to $1.0 \mathrm{mM}(n=8$ experiments $)$ reduced the average AP-dependent FM1-43 release significantly in both miniature-loaded (by 25\%; $p<0.005 ; n=335$ ) and AP-loaded (by $34 \% ; p<0.001 ; n=822$ ) synapses (Fig. 6A,B). Conversely, increasing $\left[\mathrm{Ca}^{2+}\right]_{\mathrm{o}}$ from 2.5 to $5.0 \mathrm{~mm}(n=12$ experiments) significantly enhanced AP-dependent release in miniature-loaded (by $24 \%$; $p<0.001 ; n=440$ ) and AP-loaded (by 43\%; $p<0.001$; $n=603$ ) boutons (Fig. 6C,D). These results suggest that $P_{\text {rel }}$ could be altered in a $\left[\mathrm{Ca}^{2+}\right]_{\mathrm{o}}$-dependent manner.

We then analyzed how $\left[\mathrm{Ca}^{2+}\right]_{0}$ affected the difference in unloading rates between synapse populations loaded by miniature activity versus (AP-loaded) controls. When decreasing $\left[\mathrm{Ca}^{2+}\right]_{\mathrm{o}}$ to $1 \mathrm{~mm}$ during stimulation, we observed a significant difference in the mean release rate (mean difference, 39\%; $p<0.0001$, unpaired $t$ test) between the two groups (Fig. 6A,B). This mean difference $(39 \%)$ exceeded the one obtained when comparing unloading between the groups in $2.5 \mathrm{~mm}\left[\mathrm{Ca}^{2+}\right]_{\mathrm{o}}$ (24\%; Fig. 5). Conversely, elevating $\left[\mathrm{Ca}^{2+}\right]_{0}$ to $5 \mathrm{~mm}$ during stimulation reduced the difference in mean release rates between groups to a nonsignificant level (mean difference, $7 \% ; p>0.05$, unpaired $t$ test) (Fig. 6C,D). Whereas the AP-dependent unloading rates of controls increased by on average $85 \%$ when elevating from 1 to 5 $\mathrm{mm}$, the unloading rates of miniature-loaded sites increased at the same time by only $45 \%$. This data suggests that synapses with high levels of miniature activity possess on average a high initial $P_{\text {rel }}$ (compared with controls) that restricts further increases by elevation of $\left[\mathrm{Ca}^{2+}\right]_{0}$.

\section{The probability for miniature and AP-dependent release is correlated at single CNS synapses}

To more directly determine the relationship between miniature and evoked release probability, we designed experiments to directly measure both parameters at the same synapse (see Materials and Methods; Fig. 7A). Therefore, synapses were first loaded using a field stimulation protocol (four $10 \mathrm{~Hz}$ trains of 300 APs) that was expected to saturate vesicle pools with FM1-43 (Ryan and Smith, 1995) and then unloaded by field stimulation (Fig. 7A, Trial 1). Consecutively, the same synapse population was exposed to FM1-43 under miniature activity-promoting conditions (Fig. $7 A$, Trial 2). An automated procedure selected synapses for analysis that showed both significant AP-dependent and -independent FM1-43 turnover (see Materials and Methods). This approach allowed us to independently measure APdependent $P_{\text {rel }}$ (i.e., the amount of FM1-43 release in response to field stimulation) and miniature $P_{\text {rel }}$ (i.e., the amount of FM1-43 uptake by miniature activity $=P_{\text {mini }}$ ) at the same synapse (see Appendix, Eqs. 3, 4).

Using this protocol, we were able to identify presynaptic boutons that loaded FM1-43 into their vesicle pools with both AP stimulation and miniature activity ( $n=143$ boutons; seven experiments). Analysis of the stimulus-evoked dye release at these sites demonstrated a significant positive correlation $(r=0.59 ; p<$ $0.0001)$ between AP-dependent release probability $\left(P_{\text {rel }}\right.$; FM1-43 released during $15 \mathrm{sec}$ of $2 \mathrm{~Hz}$ stimulation) and miniature frequency $\left(P_{\text {mini }}\right.$; FM1-43 uptake during 10 min exposure in high 

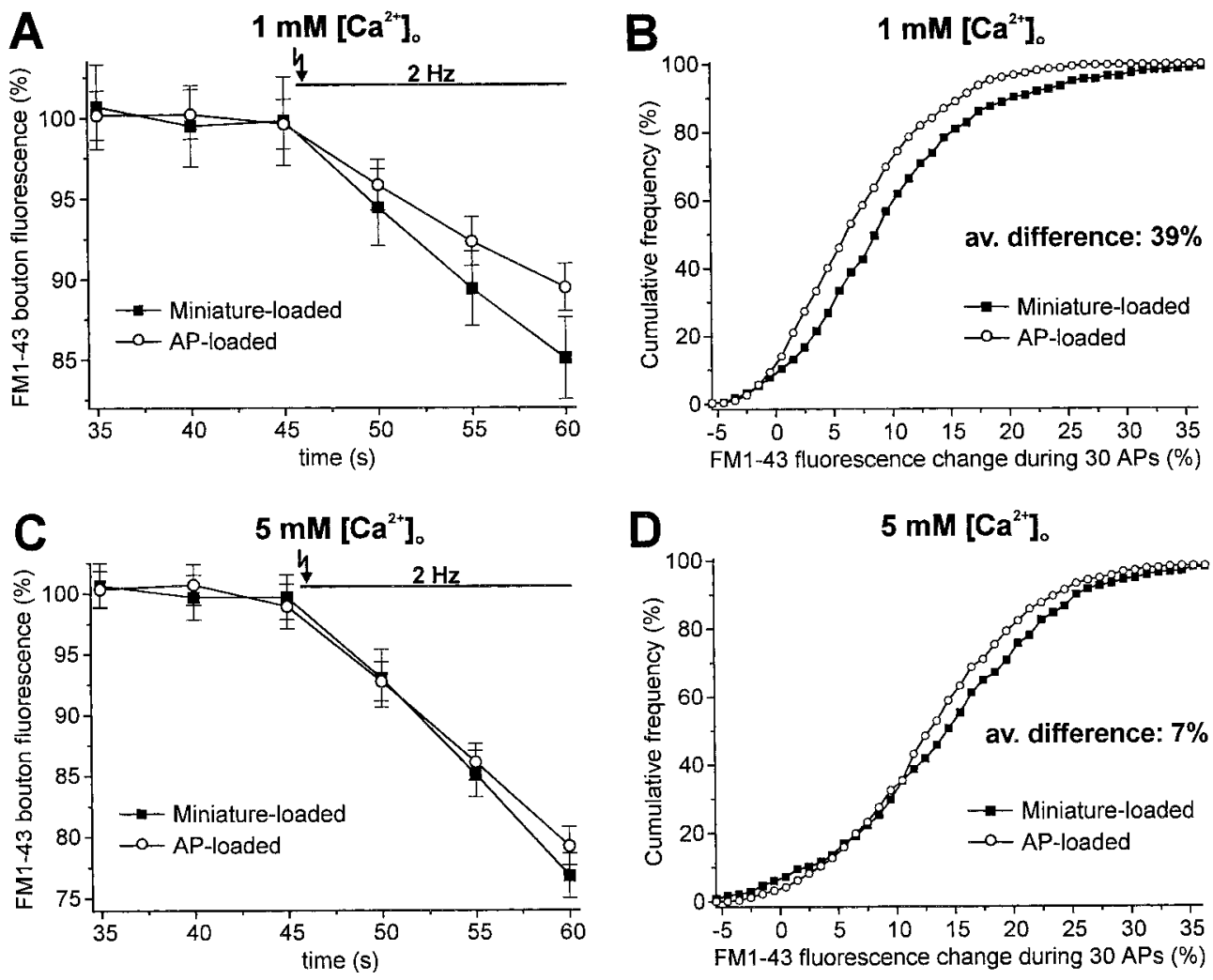

D

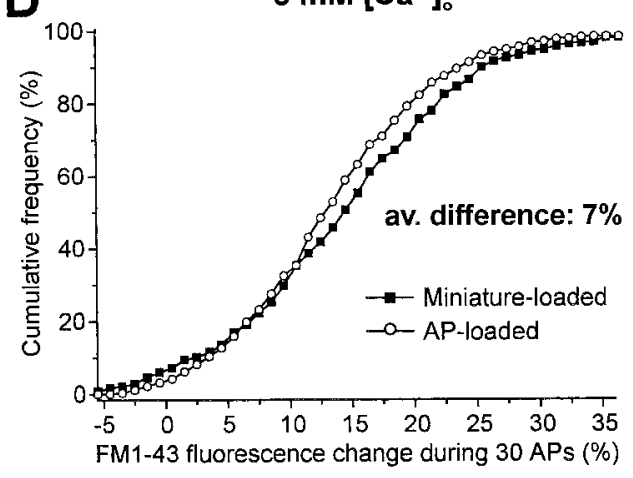

Figure 6. The difference in release rates between synapses with high miniature activity and controls is dependent on $\left[\mathrm{Ca}^{2+}\right]_{\mathrm{o}}$. FM1-43 loading was performed for two groups of synaptic boutons using specific loading protocols as described above (Fig. 1). For AP-evoked FM1-43 unloading, $\left[\mathrm{Ca}^{2+}\right]_{\mathrm{o}}$ levels were changed to alter release probability as indicated. $A, B$, Conditions of reduced release probability $\left(1.0 \mathrm{~mm}\left[\mathrm{Ca}^{2+}\right]_{\mathrm{o}}\right)$. Average trace $(A)$ and cumulative frequency plot $(B)$ of FM1-43 release during the first $15 \mathrm{sec}$ of AP-producing field stimulation. The difference in the average release rate between sites loaded by high miniature activity (Miniatureloaded) and (AP-loaded) controls is $39.1 \%$; it is larger than the difference in $2.5\left[\mathrm{Ca}^{2+}\right]_{\mathrm{o}}$ (compare with Fig. 5). C, D, Conditions of high release probability $\left(5.0 \mathrm{~mm}\left[\mathrm{Ca}^{2+}\right]_{\mathrm{o}}\right)$. Averaged trace $(C)$ and cumulative frequency plot $(D)$ of FM1-43 release during the first $15 \mathrm{sec}$ of stimulation. The average FM1-43 release rate is not significantly different between the groups $(7 \% ; p>0.05$; unpaired $t$ test). Lightning bolt depicts onset of AP-inducing field stimulation. Error bars indicate SEM.
$\left[\mathrm{Ca}^{2+}\right]_{\mathrm{o}} / \mathrm{TTX}$ ) at single boutons (Fig. 7B). A similar positive correlation between $P_{\text {rel }}$ and $P_{\text {mini }}(r=0.58 ; p<0.0001)$ was found when normalizing the FM1-43 release amounts to the median value in each trial before pooling the data (data not shown), indicating that the relationship was not caused by differences in absolute release amounts between experiments. These findings suggested that AP-evoked and AP-independent miniature release rates are co-regulated at synaptic boutons.

\section{Miniature activity and AP-dependent release probability are functions of vesicle pool size}

As outlined above (see Materials and Methods), we used a field stimulus protocol that was expected to result in complete loading of synaptic vesicle pools (Ryan and Smith, 1995) (Fig. 7A) to provide us with a measure of vesicle pool size, and thus synapse size (Henkel et al., 1996). Using this approach, we estimated the size of the $(n=143)$ presynaptic boutons that were consecutively reloaded in a miniature activity-promoting medium (see above section, Fig. $7 A$ ). Comparison between this measure of synapse size (the total amount of releasable fluorescence) and the measure of miniature frequency (the amount of FM1-43 uptake by miniature activity $=P_{\text {mini }}$ ) indicated that both parameters were significantly correlated $(r=0.64 ; p<0.0001)$ at single synaptic sites (Fig. 8). This suggested that the size of the synaptic bouton is related to the extent of spontaneous release and, hence, that larger synapses on average possess higher levels of miniature synaptic activity. A similar correlation was found between synapse (vesicle pool) size and AP-dependent release probability at single synaptic boutons ( $r=0.57$; $p<0.0001$; data not shown), confirming previously reported findings (Rosenmund and Stevens, 1996; Murthy et al., 1997).

Because the vesicle pool size of a synapse is inversely proportional to its fractional release rate (see Appendix, Eq. 2), we compared vesicle pool sizes between boutons with high rates of miniature synaptic activity and a control population. This comparison is important because the reported difference in fractional release rates (Figs. 5, 6) could potentially be caused by a systematic difference in the average pool size of the groups (see Appendix, Eq. 2). Therefore, from the experiments shown in Figures 7 and 8 , a control population of synapses was selected solely based on its FM1-43 unloading response to AP-inducing field stimulation (Fig. 7A, Trial 1). The synaptic vesicle pool size of this group was compared with the pool size of synapses that, in addition to fulfilling the response criterion for controls, also exhibited significant FM1-43 uptake with miniature activity in the reloading trial (Fig. 7A, Trial 2). This experiment differs from those presented in Figures 5 and 6 in that synapses with high miniature activity and control synapses were selected from the same culture (synapse population) and were loaded using identical protocols. After normalizing the AP-mediated FM1-43 fluorescence release to the amount of loading (see Appendix, Eq. 2), we found that sites with high miniature activity release $20 \%$ more FM1-43 during 30 pulses of $2 \mathrm{~Hz}$ AP stimulation than the control group ( $p<$ 0.0001 , unpaired $t$ test). This value is comparable to that reported comparing sister cultures loaded with different protocols $(24 \%$; Fig. 5C). This finding confirms that the proportionality between release probability and vesicle pool size (see Appendix, Eq. 2) differs between the groups of synapses with high miniature activity and controls. Furthermore, comparison of the average vesicle pool size between these two groups demonstrated that vesicle pools were significantly larger at synapses with high miniature activity (difference in size, 29\%; $p<0.0001$; Mann-Whitney $U$ test) (Fig. 9A). This indicates that the difference in the fractional release rates between synapses with high miniature activity and control synapses cannot be accounted for by a relative larger size of control synapses. In fact, the relatively larger average size of miniature-loaded boutons (compared with controls) suggests that 


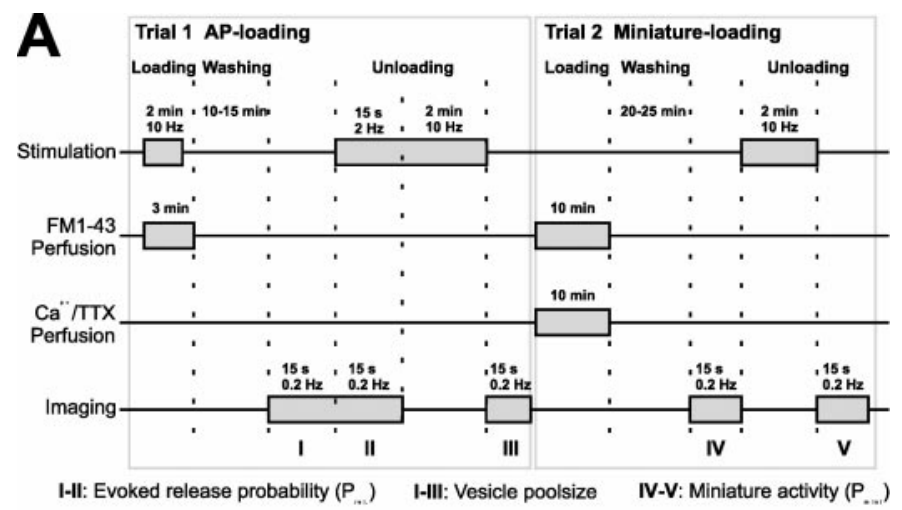

\section{B}

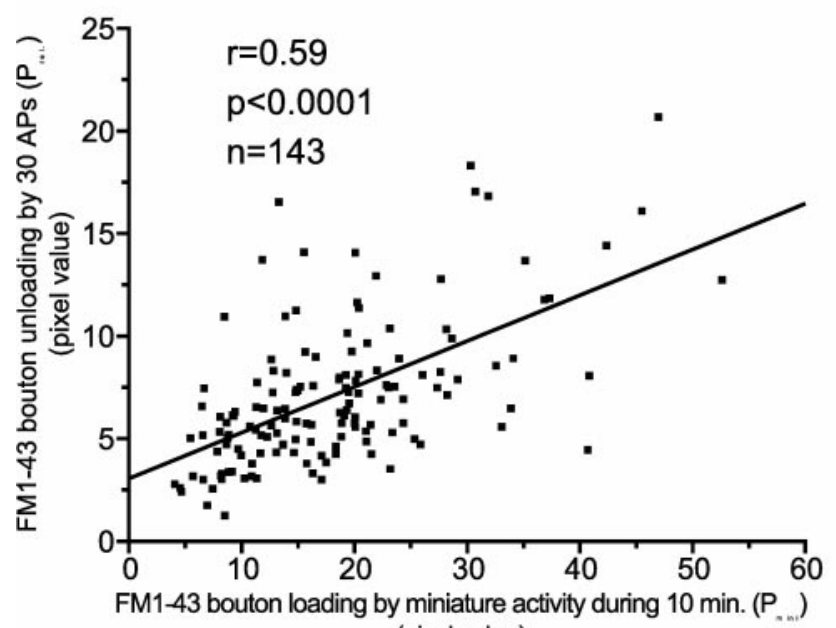

(pixel value)

Figure 7. Measures of AP-evoked release probability and miniature release probability are positively correlated at single synaptic boutons. $A$, Synaptic boutons were loaded with FM1-43 using a large number of AP-inducing field stimuli $(4 \times 300)$ to saturate vesicle pools (Trial 1 AP-loading). After washing, the change in FM1-43 fluorescence during 30 APs was recorded as a measure of evoked release probability $\left(P_{\text {rel }}\right)$. After this measurement, the same synapse population was reloaded with FM1-43 under miniature activity-promoting conditions $\left(5 \mathrm{mM} \mathrm{Ca}^{2+} / 0.6\right.$ $\mu \mathrm{M}$ TTX) for $10 \mathrm{~min}$ (Trial 2 Miniature-loading). The amount FM1-43 fluorescence uptake during that time was a measure of the probability of miniature activity $\left(P_{\operatorname{mini}}\right)$ of the synapse. An automated criterion was applied to select responsive from nonresponsive sites in both trials (see Materials and Methods). $B$, A significant positive correlation between $P_{\text {mini }}$ and $P_{\text {evoked }}(r=0.59 ; p<0.0001)$ was observed at $(n=143)$ synaptic boutons (7 experiments).

the difference in $P_{\text {rel }}$ between the groups (calculated based on fractional release rates; see Appendix, Eq. 2) is likely an underestimate, because fractional release in inversely proportional to pool size. Accordingly, we compared the absolute amounts of evoked FM1-43 release during AP stimulation between the two groups. Absolute FM1-43 release is a measure for $P_{\text {rel }}$ that is not influenced by the vesicle pool size of the synapse (see Appendix, Eq. 3). This comparison showed that boutons with high rates of miniature activity release on average 59\% more FM1-43 fluorescence per stimulus than the control group recruited from same population of synapses (Fig. 9B).

\section{DISCUSSION}

We have used confocal imaging of the vesicular turnover marker FM1-43 to study evoked transmitter release at synapses with high

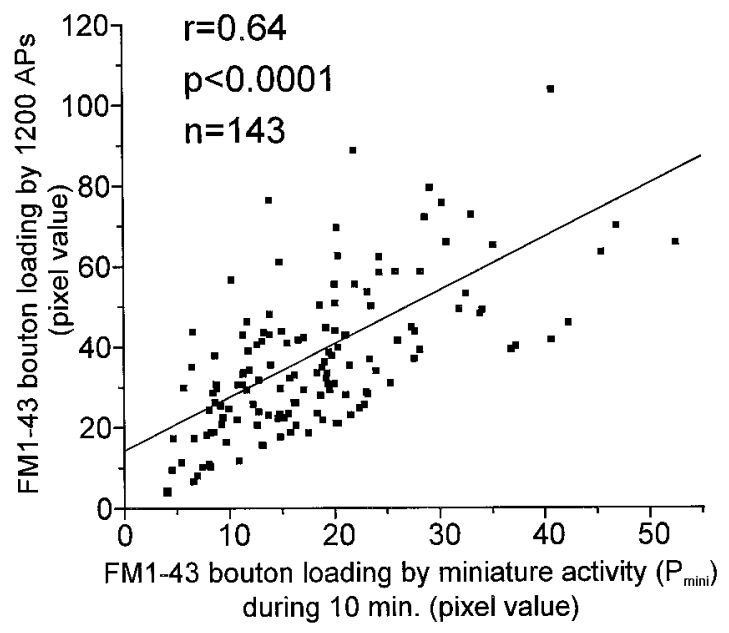

Figure 8 . The probability for miniature activity is positively correlated with a measure of bouton size. Data from the same experiments shown in Figure 7. A significant positive correlation $(r=0.64 ; p<0.0001)$ is found between the amount of FM1-43 uptake during 10 min incubation in a miniature activity-promoting medium $\left(P_{\text {mini }}\right)$ and the amount of FM1-43 loading by 1200 APs, a measure of bouton size.

rates of miniature synaptic activity. Using this experimental approach to directly measure transmitter release rather than its postsynaptic effect, we were able compare the AP-dependent release efficacies among single synaptic sites. The use of FM1-43 as a vesicle-turnover marker has two important advantages for our study: it allowed us (1) to selectively stain synapses with high miniature activity; and (2) to compare the release rates between individual synapses under conditions that are not affected by postsynaptic responsiveness. Our results indicate that synapses with high rates of miniature activity possess on average enhanced AP-evoked release probabilities when compared with controls. Furthermore, by directly measuring both the probability of miniature synaptic activity and AP-evoked release at the same synapse, we find that the two parameters are significantly correlated. These findings suggest a co-regulation of miniature synaptic activity and AP-evoked release probability at presynaptic terminals. Therefore, miniature rates may indicate the readiness of the vesicle release machinery to discharge a transmitter quanta in the presence of an appropriate stimulus.

Miniature synaptic activity has been well described in the CNS and PNS. However, it remains to be shown whether miniature synaptic activity serves a specific function in synaptic transmission or is just a stochastic process. Because miniature synaptic activity is modifiable (Malgaroli and Tsien, 1992; Chavis et al., 1998), it argues for the first point. Furthermore, recent findings indicate that at some synapse types miniature activity is involved in the developmental formation (Gottmann et al., 1994; O'Brien et al., 1997) as well as in the structural maintenance of synaptic connections (McKinney et al., 1999). As rates of miniature synaptic activity are upregulated after the induction of short-term (Kamiya and Zucker, 1994; Cummings et al., 1996; for review, see Zucker, 1996; Fisher et al., 1997) and long-term (Minota et al., 1991; Malgaroli and Tsien, 1992; Arancio et al., 1995; Tong et al., 1996; Chen and Regehr, 1997; but see Cormier and Kelly, 1996) synaptic enhancement, a possible role for miniature release could be the selective maintenance of such synaptic connections that have received context relevant priming in an activity-dependent manner. There are additional findings indicating that miniature 

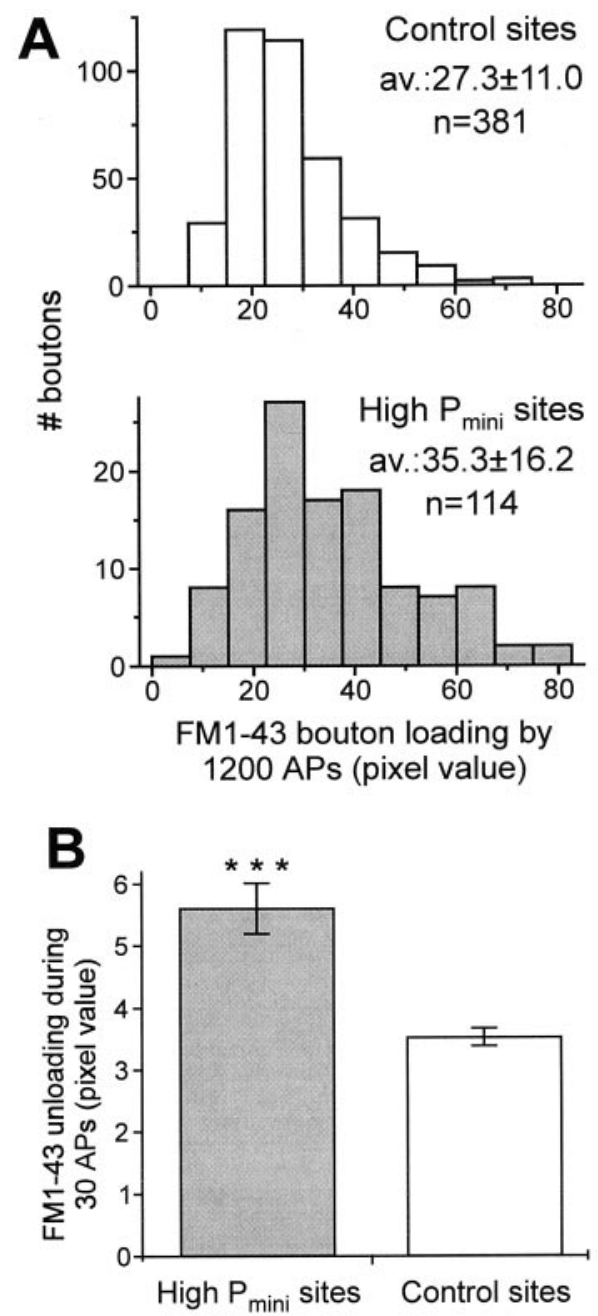

Figure 9. Boutons with high levels of miniature synaptic activity possess larger vesicle pools and release more vesicles per stimulus train. Synapse (vesicle pool) size and release probability $\left(P_{\text {rel }}\right)$ were compared between two groups of boutons recruited from an identical population using the reloading protocol described above (Fig. $7 A$ ). Both groups had to show FM1-43 uptake and release during AP stimulation and were sorted based on their ability to reload FM1-43 under miniature synaptic activitypromoting conditions. To pass the automated selection procedure in each respective trial, the baseline variation of the boutons had to be $<10 \%$ of its total releasable fluorescence (Fig. 2). A, Histograms of bouton sizes measured by FM1-43 bouton loading with 1200 APs (bin size $=7.5$ pixel values). Top panel, Bouton sizes of control sites $(n=381)$ that were selected based on their response to field stimulation. Bottom panel, Bouton sizes of synapses $(n=114)$ that, in addition to matching the criterion for the control group, showed significant FM1-43 uptake under miniature activity-promoting conditions (high $P_{\text {mini }}$ sites). Significant difference $(29 \% ; p<0.0001$, Mann-Whitney $U$ test) in the average bouton size between the two groups. $B$, The average amount of FM1-43 release in response to 30 APs was compared between the two groups in shown in $A$. Note that this measure of $P_{\text {rel }}$ is independent of bouton size (see Appendix, Eq. 3). Evoked FM1-43 release is increased by 59\% ( $p<0.0001$, Mann-Whitney $U$ test) at boutons with high miniature synaptic activity (high $P_{\text {mini }}$ sites) compared with controls.

and evoked release probability are co-regulated at synaptic terminals. For example, inhibition of synaptotagmin in cholinergic synapses (Mochida et al., 1997), activation of muscarinic receptors on GABAergic neurons (Baba et al., 1998), BDNF treatment of hippocampal cells ( $\mathrm{Li}$ et al., 1998), and activation of cannabinoid receptors on Purkinje cells (Levenes et al., 1998) all induce parallel modulation of miniature and evoked release rates. Our results support findings of an activity-dependent co-regulation of both miniature and evoked transmitter release by showing (1) that synapses with high miniature activity possess on average significantly enhanced AP-dependent release rates (Figs. 5, 6, 9B); and (2) that there exists a correlation between miniature and evoked release probability at single synapses (Fig. $7 B$ ).

Miniature release can be regulated in a $\left[\mathrm{Ca}^{2+}\right]_{\mathrm{i}}$-independent manner by agents that directly affect the presynaptic release machinery, e.g., $\alpha$-latrotoxin (Ceccarelli et al., 1988; Capogna et al., 1996a,b) or ruthenium red (Trudeau et al., 1996). However, under physiological conditions, a strong $\left[\mathrm{Ca}^{2+}\right]_{\mathrm{i}}$ dependence of miniature synaptic activity is well documented (Matthews and Wickelgren, 1977; Marcus et al., 1992; Doze et al., 1995; Katz et al., 1995; Scanziani et al., 1995; Capogna et al., 1996a, 1997; Poisbeau et al., 1996; Schoppa and Westbrook, 1997; Bao et al., 1998; Li et al., 1998). Using somatic recordings, we confirmed these findings by showing significantly enhanced rates of miniature activity after the elevation of $\left[\mathrm{Ca}^{2+}\right]_{\mathrm{o}}$ from 0 to $5 \mathrm{~mm}$ (see Results). Accordingly, we found that $\left[\mathrm{Ca}^{2+}\right]_{\mathrm{o}}$ elevation from 0 to $5 \mathrm{~mm}$ lead to a significant increase in the number boutons that were labeled by FM1-43 with miniature synaptic activity. These results are consistent with findings by Chavis et al. (1998) and Ma et al. (1999), suggesting that activation of the cAMP-dependent protein kinase PKA, a downstream target of $\mathrm{Ca}^{2+}$, induces vesicular cycling at previously inactive uptake sites. A small number of synapses $(\sim 1 \%)$, however, showed continued high rates of FM1-43 uptake by miniature activity under nominally $\left[\mathrm{Ca}^{2+}\right]_{\mathrm{o}}$-free conditions comparable to those rates achieved in high $\left[\mathrm{Ca}^{2+}\right]_{0}$. This surprising finding indicates that a subpopulation of synapses can sustain high rates of miniature activity even in low $\left[\mathrm{Ca}^{2+}\right]_{0}$. The inability to resolve a difference in the amount of FM1-43 uptake between the two groups loaded in high versus low $\left[\mathrm{Ca}^{2+}\right]_{\mathrm{o}}$ may also be attributed to the use of an automated criterion that selects synapses only if they show a sufficient signalto-noise ratio (see Materials and Methods).

In contrast to AP-dependent release (Haage et al., 1998), $\mathrm{Ca}^{2+}$ seems to mediate its effects on miniature release by entry through low-threshold rather than high-threshold VGCCs (Parfitt and Madison, 1993; Momiyama and Takahashi, 1994; Scanziani et al., 1995; Bao et al., 1998), indicating the existence of differential control mechanisms over both forms of transmitter release. Moreover, $\mathrm{Ca}^{2+}$ does not seem to act directly on the release machinery to mediate miniature release, but rather indirectly through activation of second messenger systems such as PKC (Malenka et al., 1986; Parfitt and Madison, 1993; Capogna et al., 1995; Stevens and Sullivan, 1998; Carroll et al., 1998) and PKA (ChavezNoriega and Stevens, 1994; Capogna et al., 1995; Carroll et al., 1998; Chavis et al., 1998). Kondo and Marty (1997) and Chen and Regehr (1997) show that PKA activation alone is sufficient to stimulate miniature synaptic release even in the absence of $\left[\mathrm{Ca}^{2+}\right]_{\mathrm{o}}$. There are additional findings indicating the existence of molecular pathways that differentially affect miniature and evoked release, including the activation of noradrenaline (Kondo and Marty, 1998) and adenosine (Dittman and Regehr, 1996) receptors and the differential regulation of release machinery proteins (Deitcher et al., 1998; Hua et al., 1998). If differential mechanisms exist to independently regulate miniature and evoked transmitter release, how could a co-regulation of both forms of release be achieved? A plausible explanation would be an activity-dependent switch from separate to parallel regulation of miniature and evoked release. Such a switch could conceivably 
be induced by a strong stimulus (e.g., pulse train) triggering the activation of common intracellular second-messengers, e.g., upregulation of PKA (Byrne and Kandel, 1996; Tong et al., 1996; Chavis et al., 1998; Lonart and Südhof, 1998; Villacres et al., 1998) or PKC (Leahy et al., 1993; Ramakers et al., 1997; Majewski and Iannazzo, 1998) above a certain threshold. An activitydependent switch from separate to parallel regulation of evoked and miniature release is supported by findings showing that after parallel upregulation of miniature and evoked release rates, miniature synaptic release also becomes sensitive to agents that block high-threshold VGCCs (Scanziani et al., 1995).

It has been suggested that a potential mechanism for controlling synaptic activity is the regulation of synaptic structure (Calverley and Jones, 1990; Bailey and Kandel, 1993; Lisman and Harris, 1993; Harris and Sultan, 1995; Edwards, 1995; Buchs and Müller, 1996; Rusakov et al., 1997; Mackenzie et al., 1999). Our results indicate that the degree of miniature synaptic activity is positively correlated with the size of the vesicle pool (Fig. 8), and thus the size of the synaptic terminal (Henkel et al., 1996). Correspondingly, we find that synapses with high levels of miniature activity are on average larger than synapses drawn from a control population (Fig. 9A). These results confirm findings that show a similar relationship between synapse size and APdependent release efficacy (Murthy et al., 1997; Prange and Murphy, 1999). Furthermore, they suggest a model in which the frequency of miniature release can be controlled by the number of readily releasable and/or docked vesicles, both parameters which significantly correlate with terminal size (Dobrunz and Stevens, 1997; Schikorski and Stevens, 1997). Hence, modifications of synaptic structure could build the anatomical basis for controlling evoked and miniature release rates.

\section{APPENDIX}

We have used the after equations to describe the relationship between stimulus-evoked FM1-43 release and release probability in our experiments:

$$
F_{\text {rel }}=P_{\text {rel }} \times\left(\operatorname{Ves}_{\mathrm{FM} 1-43} / \operatorname{Ves}_{\text {total }}\right) \times F_{\text {ves }}
$$

Equation 1 describes the proposed relationship between the amount of FM1-43 released per stimulus $\left(F_{\text {rel }}\right)$, the proportion of FM1-43-loaded vesicles $\left(\operatorname{Ves}_{\mathrm{FM} 1-43}\right)$ to the total size of the vesicle pool $\left(V e s_{\text {total }}\right)$, and the fluorescence of a single vesicle $\left(F_{\text {ves }}\right)$, a constant. The number of FM1-43-loaded vesicles (Ves FM1-43 $_{\text {F }}$ ) was expected to differ depending on the protocol used for FM1-43 loading (AP loading vs miniature loading). Therefore, to compare the FM1-43 release rates between AP- and miniatureloaded groups the amount of FM1-43 release per stimulus $\left(F_{\text {rel }}\right)$ was normalized to the total amount of FM1-43-loaded vesicles $\left(\right.$ Ves $\left._{\mathrm{FM} 1-43}\right)$ at each synapse:

$$
F_{\text {rel }} \text { norm }=\left(P_{\text {rel }} / V e s_{\text {total }}\right) \times F_{\text {ves }}
$$

Equation 2 was derived from Equation 1 by dividing by $V e s_{\mathrm{FM} 1-43}$ and shows that the normalized (fractional) rate of stimulus evoked fluorescence $\left(F_{\text {rel }}(\right.$ norm $\left.)=F_{\text {rel }} / V e s_{\mathrm{FM} 1-43}\right)$ is directly proportional to the release probability $\left(P_{\text {rel }}\right)$ and inversely proportional to the total size of the vesicle pool (Ves $\left.s_{\text {total }}\right)$.

$$
F_{\text {rel }}=P_{\text {rel }} \times F_{\text {ves }}
$$

Equation 3 shows the relationship between the amount of FM1-43 released per stimulus $\left(F_{\text {rel }}\right)$ and the release probability $\left(P_{\text {rel }}\right)$ for experiments in which a large number of stimuli $(4 \times$
300) were used to saturate synaptic vesicle pools with FM1-43 (Ryan and Smith, 1995). In this case, the number of FM1-43loaded vesicles $\left(\operatorname{Ves}_{\mathrm{FM} 1-43}\right)$ would approach the total size of the vesicle pool $\left(\right.$ Ves $\left._{\text {total }}\right)$ and, hence, amount of fluorescence released per stimulus $\left(F_{\text {rel }}\right)$ would be directly proportional to the release probability $\left(P_{\text {rel }}\right)$. This equation was derived from Equation 1 setting $\left(\right.$ Ves $_{\mathrm{FM} 1-43} /$ Ves $\left._{\text {total }}\right)=1$.

$$
F_{\text {uptake }}=P_{\text {rel }} \times F_{\text {ves }}
$$

Equation 4 describes the relationship between the amount of FM1-43 uptake $\left(F_{\text {uptake }}\right)$ and release probability $\left(P_{\text {rel }}\right)$ (Murthy et al., 1997, their Eq. 1). The equation is essentially derived from Equation 3 by replacing $F_{\text {rel }}$ with $F_{\text {uptake. }}$ This can be done under the following conditions: (1) vesicle exocytosis and endocytosis are matched, i.e., for each vesicle released one vesicle will be retrieved. This is most likely the case for $\left[\mathrm{Ca}^{2+}\right]_{0}$ used in our experiments (Smith and Betz, 1996; Gad et al., 1998; Rouze and Schwarz, 1998). (2) FM1-43-loaded vesicles intermingle with the rest of the pool and are not preferably released. This has been indicated by Ryan and Smith (1995). (3) $F_{\text {uptake }}$ is not maximal, so it is not limited by the pool size. This is most likely the case in experiments using miniature activity for FM1-43 uptake, as even the highest miniature rates $(\sim 0.1 \mathrm{~Hz}$; Wang et al., 1999$)$ are not expected to turnover the entire vesicle pool during $10 \mathrm{~min}$. Hence, in experiments analyzing absolute amounts of FM1-43 fluorescence uptake in a miniature-promoting medium, we have used $F_{\text {uptake }}$ as a measure of miniature activity and thus miniature $P_{\text {rel }}$, termed $P_{\text {mini }}$.

\section{REFERENCES}

Arancio O, Kandel ER, Hawkins RD (1995) Activity-dependent longterm enhancement of transmitter release by presynaptic $3^{\prime}, 5^{\prime}$-cyclic GMP in cultured hippocampal neurons. Nature 376:74-80.

Baba H, Kohno T, Okamoto M, Goldstein PA, Shimoji K, Yoshimura M (1998) Muscarinic facilitation on GABA release in substantia gelatinosa of the rat spinal dorsal horn. J Physiol (Lond) 508:83-93.

Bailey CH, Kandel ER (1993) Structural changes accompanying memory storage. Annu Rev Physiol 55:397-426.

Bao J, Li JJ, Perl ER (1998) Differences in $\mathrm{Ca}^{2+}$ channels governing generation of miniature and evoked excitatory synaptic currents in spinal laminae 1 and 2. J Neurosci 18:8740-8750.

Betz WJ, Bewick GS (1992) Optical analysis of synaptic vesicle recycling at the frog neuromuscular junction. Science 255:200-203.

Betz WJ, Bewick GS (1993) Optical monitoring of transmitter release and synaptic vesicle recycling at the frog neuromuscular junction. J Physiol (Lond) 460:287-309.

Betz WJ, Mao F, Smith CB (1996) Imaging exocytosis and endocytosis. Curr Opin Neurobiol 6:365-371.

Buchs PA, Müller D (1996) Induction of long-term potentiation is associated with major ultrastructural changes of activated synapses. Proc Natl Acad Sci USA 93:8040-8045.

Byrne JH, Kandel ER (1996) Presynaptic facilitation revisited: state and time dependence. J Neurosci 16:425-435.

Calverley RK, Jones DG (1990) Contributions of dendritic spines and perforated synapses to synaptic plasticity. Brain Res Brain Res Rev 15:215-249.

Capogna M, Gähwiler BH, Thompson SM (1995) Presynaptic enhancement of inhibitory synaptic transmission by protein kinase $\mathrm{A}$ and $\mathrm{C}$ in the rat hippocampus. J Neurosci 15:1249-1260.

Capogna M, Gähwiler BH, Thompson SM (1996a) Presynaptic inhibition of calcium-dependent and -independent release elicited with ionomycin, gadolinium, and $\alpha$-latrotoxin in the hippocampus. J Neurophysiol 75:2017-2028.

Capogna M, Gähwiler BH, Thompson SM (1996b) Calciumindependent actions of $\alpha$-latrotoxin on spontaneous and evoked synaptic transmission in the hippocampus. J Neurophysiol 76:3149-3158.

Capogna M, McKinney RA, O'Connor V, Gähwiler BH, Thompson SM (1997) $\mathrm{Ca}^{2+}$ or $\mathrm{Sr}^{2+}$ partially rescues synaptic transmission in hip- 
pocampal cultures treated with botulinum toxin $\mathrm{A}$ and $\mathrm{C}$, but not tetanus toxin. J Neurosci 17:7190-7202.

Carroll R, Nicoll RA, Malenka RC (1998) Effect of PKA and PKC on miniature excitatory postsynaptic currents in CA1 pyramidal cells. J Neurophysiol 80:2797-2800.

Ceccarelli B, Hurlbut WP, Iezzi N (1988) Effect of $\alpha$-latrotoxin on the frog neuromuscular junction at low temperature. J Physiol (Lond) 402:195-217.

Chavez-Noriega LE, Stevens CF (1994) Increased transmitter release at excitatory synapses produced by direct activation of adenylate cyclase in rat hippocampal slices. J Neurosci 14:310-317.

Chavis P, Mollard P, Bockaert J, Manzoni O (1998) Visualization of cyclic AMP-regulated presynaptic activity at cerebellar granule cells. Neuron 20:773-781.

Chen C, Regehr WG (1997) The mechanism of cAMP-mediated enhancement at a cerebellar synapse. J Neurosci 22:8687-8694.

Cormier RJ, Kelly PT (1996) Glutamate-induced long-term potentiation enhances spontaneous EPSC amplitude but not frequency. J Neurophysiol 75:1909-1918.

Cummings DD, Wilcox KS, Dichter MA (1996) Calcium-dependent paired-pulse facilitation of miniature EPSC frequency accompanies depression of EPSCs at hippocampal synapse in culture. J Neurosci 16:531-523.

Deitcher DL, Ueda A, Stewart BA, Burgess RW, Kidokoro Y, Schwarz TL (1998) Distinct requirements for evoked and spontaneous release of neurotransmitter are revealed by mutations in the Drosophila gene neuronal-synaptobrevin. J Neurosci 18:2028-2039.

Dittman JS, Regehr WG (1996) Contributions of calcium-dependent and calcium-independent mechanisms to presynaptic inhibition at a cerebellar synapse. J Neurosci 16:1623-1633.

Dobrunz LE, Stevens CF (1997) Heterogeneity of release probability, facilitation and depletion at central synapses. Neuron 18:995-1008.

Dodge FA, Rahamimoff R (1967) Co-operative action of calcium ions in transmitter release at the neuromuscular junction. J Physiol (Lond) 193:419-432.

Doze VA, Cohen GA, Madison DV (1995) Calcium channel involvement in $\mathrm{GABA}_{\mathrm{B}}$ receptor-mediated inhibition of GABA release in area CA1 of the rat hippocampus. J Neurophysiol 74:43-53.

Edwards FA (1995) Anatomy and electrophysiology of fast central synapses lead to a structural model for long-term potentiation. Physiol Rev 75:759-787.

Fisher SA, Fischer TM, Carew TJ (1997) Multiple overlapping processes underlying short-term synaptic enhancement. Trends Neurosci:170-177.

Frerking M, Borges S, Wilson M (1997) Are some minis multiquantal? J Neurophysiol 78:1293-1304.

Gad H, Low P, Zotova E, Brodin L, Shupliakov O (1998) Dissociation between $\mathrm{Ca}^{2+}$-triggered synaptic vesicle exocytosis and clathrinmediated endocytosis at a central synapse. Neuron 21:607-616.

Ghiradi M, Braha O, Hochner B, Montarolo PG, Kandel ER, Dale N (1992) Roles of PKA and PKC in facilitation of evoked and spontaneous transmitter release at depressed and nondepressed synapses in Aplysia sensory neurons. Neuron 9:479-489.

Gottmann K, Pfrieger FW, Lux HD (1994) The formation of glutamatergic synapses in cultured central neurons: selective increase in miniature synaptic currents. Brain Res Dev Brain Res 81:77-88.

Haage D, Karlsson U, Johansson S (1998) Heterogeneous presynaptic $\mathrm{Ca}^{2+}$ channels types triggering GABA release onto medial preoptic neurons from rat. J Physiol (Lond) 507:77-91.

Hamill OP, Marty A, Neher E, Sakmann B, Sigworth F (1981) Improved patch-clamp techniques for high resolution current recordings from cells and cell free membrane patches. Pflügers Arch 391:85-100.

Harris KM, Sultan P (1995) Variation in the number, location and size of synaptic vesicles provides an anatomical basis for the nonuniform probability of release at hippocampal CA1 synapses. Neuropharmacology 34:1387-1395.

Hell JW, Yokoyama CT, Breeze LJ, Chavkin C, Catterall WA (1995) Phosphorylation of presynaptic and postsynaptic calcium channels by cAMP-dependent protein kinase in hippocampal neurons. EMBO J 14:3036-3044.

Henkel AW, Lübke J, Betz WJ (1996) FM1-43 dye ultrastructural localization in and release from frog motor nerve terminals. Proc Natl Acad Sci USA 93:1918-1923.
Hua SY, Raciborska DA, Trimble WS, Charlton MP (1998) Different VAMP/Synaptobrevin complexes for spontaneous and evoked transmitter release at the crayfish neuromuscular junction. J Neurophysiol 80:3233-3246.

Kamiya H, Zucker RS (1994) Residual $\mathrm{Ca}^{2+}$ and short-term synaptic plasticity. Nature 371:603-606.

Katz E, Ferro PA, Cherskey BD, Sugimori M, Llinas R, Uchitel OD (1995) Effects of Ca2 + channel blockers on transmitter release and presynaptic currents at the for neuromuscular junction. J Physiol (Lond) 486:695-706.

Kondo S, Marty A (1997) Protein kinase A-mediated enhancement of miniature IPSC frequency by noradrenaline in rat cerebellar stellate cells. J Physiol (Lond) 498:165-176.

Kondo S, Marty A (1998) Differential effects of noradrenaline on evoked, spontaneous and miniature IPSCs in rat cerebellar stellate cells. J Physiol (Lond) 509:233-243.

Leahy JC, Luo Y, Kent CS, Meiri KF, Vallano ML (1993) Demonstration of presynaptic protein kinase $\mathrm{C}$ activation following long-term potentiation in rat hippocampus. Neuroscience 52:563-574.

Levenes C, Daniel H, Soubrie P, Crepel F (1998) Cannabinoids decrease excitatory synaptic transmission and impair long-term depression in rat cerebellar Purkinje cells. J Physiol (Lond) 510:867-879.

Li YX, Zhang Y, Lester HA, Schuman EM, Davidson N (1998) Enhancement of neurotransmitter release induced by brain-derived neurotrophic factor in cultured hippocampal neurons. J Neurosci 18:10231-10240

Lisman JE, Harris KM (1993) Quantal analysis and synaptic anatomyintegrating two views of hippocampal plasticity. Trends Neurosci 16:141-147.

Liu G, Tsien RW (1995) Properties of synaptic transmission at single hippocampal boutons. Nature 375:404-408.

Lonart G, Südhof TC (1998) Region specific phosphorylation of rabphilin in mossy fiber nerve terminals of the hippocampus. J Neurosci 18:634-640.

Ma L, Zablow L, Kandel ER, Siegelbaum SA (1999) Cyclic AMP induces functional presynaptic boutons in hippocampal CA3-CA1 cultures. Nature Neurosci 2:24-30.

Mackenzie PJ, Umemiya M, Murphy TH (1996) $\mathrm{Ca}^{2+}$ imaging of CNS axons in culture indicates reliable coupling between single action potentials and distal functional release sites. Neuron 16:783-795.

Mackenzie PJ, Kenner GS, Prange O, Shayan H, Umemiya M, Murphy TH (1999) Ultrastructural correlates of quantal synaptic function at single CNS synapses. J Neurosci 19:RC13(1-7).

Majewski H, Iannazzo L (1998) Protein kinase C: a physiological mediator of enhanced transmitter output. Prog Neurobiol 55:463-475.

Malenka RC, Madison DV, Nicoll RA (1986) Potentiation of synaptic transmission in the hippocampus by phorbol esters. Nature 321:175-177.

Malgaroli A, Tsien RW (1992) Glutamate-induced long-term potentiation of the frequency of miniature synaptic currents in cultured hippocampal neurons. Nature 357:134-139.

Marcus DS, Kriebel ME, Hanna RB (1992) Effects of calcium on the dynamic process of transmitter release which generates either skew- or bell MEPPS. Brain Res 593:185-196.

Matthews G, Wickelgren WO (1977) On the effects of calcium on the frequency of miniature end-plate potentials at the frog neuromuscular junction. J Physiol (Lond) 266:91-101.

McKinney RA, Capogna M, Dürr R, Gähwiler BH, Thompson SM (1999) Miniature synaptic events maintain dendritic spines via AMPA receptor activation. Nat Neurosci 2:44-49.

Minota S, Kumamoto E, Kitakoga O, Kuba K (1991) Long-term potentiation induced by a sustained rise in the intraterminal $\mathrm{Ca}^{2+}$ in bull frog sympathetic ganglia. J Physiol (Lond) 435:421-438.

Mochida S, Fukuda M, Niinobe M, Kobayashi H, Mikoshiba K (1997) Roles of synaptotagmin $\mathrm{C} 2$ domains in neurotransmitter secretion and inositol high-polyphosphate binding at mammalian cholinergic synapses. Neuroscience 77:937-943.

Momiyama A, Takahashi T (1994) Calcium channels responsible for potassium-induced transmitter release at rat cerebellar synapse. J Physiol (Lond) 476:197-202.

Murphy TH, Baraban JM, Wier WG, Blatter LA (1994) Visualization of quantal synaptic transmission by dendritic calcium imaging. Science 263:529-532. 
Murphy TH, Baraban JM, Wier WG (1995) Mapping miniature synaptic currents to single synapses using calcium imaging reveals heterogeneity in postsynaptic output. Neuron 15:159-168.

Murthy VN, Sejnowski TJ, Stevens CF (1997) Heterogeneous release properties of visualized individual hippocampal synapses. Neuron 18:599-612.

O’Brien RJ, Mammen AL, Blackshaw S, Ehlers MD, Rothstein JD, Huganir RL (1997) The development of excitatory synapses in cultured spinal neurons. J Neurosci 19:7339-7350.

Parfitt KD, Madison DV (1993) Phorbol esters enhance synaptic transmission by a presynaptic, calcium-dependent mechanisms in rat hippocampus. J Physiol (Lond) 471:245-268.

Poisbeau P, Rene F, Egles C, Felix JM, Feltz P, Schlichter R (1996) Characterization of functional GABAergic synapses formed between rat hypothalamic neurons and pituitary intermediate lobe cells in coculture: $\mathrm{Ca}^{2+}$ dependence of spontaneous IPSCs. J Neurosci 16:4835-4845.

Prange O, Murphy TM (1997) FM1-43 as an indicator for miniature synaptic activity at single synapses of cortical neurons. Soc Neurosci Abstr 23:2272.

Prange O, Murphy TM (1998) Comparison of evoked and miniature release at single CNS synapses in culture. Soc Neurosci Abstr 24:226.

Prange O, Murphy TM (1999) An analysis of multiquantal transmitter release from single cultured cortical neuron terminals. J Neurophysiol 81:1810-1817.

Ramakers GM, Pasinelli P, Hens JJ, Gispen WH, De Graan PN (1997) Protein kinase $\mathrm{C}$ in synaptic plasticity: changes in the in situ phosphorylation state of identified pre- and postsynaptic substrates. Prog Neuropsychopharmacol Biol Psychiatry 21:455-486.

Rosenmund C, Stevens CF (1996) Definition of the readily releasable pool of vesicles at hippocampal synapses. Neuron 16:1197-1220.

Rouze NC, Schwartz EA (1998) Continuous and transient vesicle cycling at a ribbon synapse. J Neurosci 18:8614-8624.

Rusakov DA, Davies HA, Harrison E, Diana G, Richter-Levin G, Bliss TV, Stewart MG (1997) Ultrastructural synaptic correlates of spatial learning in rat hippocampus. Neuroscience 80:69-77.

Ryan TA, Smith SJ (1995) Vesicle pool mobilization during action potential firing at hippocampal synapses. Neuron 14:983-989.
Ryan TA, Reuter H, Wendland B, Schweizer FE, Tsien RW, Smith SJ (1993) The kinetics of synaptic vesicle recycling measured at single presynaptic boutons. Neuron 11:725-738.

Ryan TA, Reuter H, Smith SJ (1997) Optical detection of a quantal presynaptic membrane turnover. Nature 388:478-482.

Scanziani M, Gähwiler BH, Thompson SM (1995) Presynaptic inhibition of excitatory synaptic transmission by muscarinic and metabotropic glutamate receptor activation in the hippocampus: are $\mathrm{Ca}^{2+}$ channels involved? Neuropharmacology 34:1549-1557.

Schikorski T, Stevens CF (1997) Quantitative ultrastructural analysis of hippocampal excitatory synapses. J Neurosci 17:5858-5867.

Schoppa NE, Westbrook GL (1997) Modulation of mEPSCs in olfactory bulb mitral cells by metabotropic glutamate receptors. J Neurophysiol $78: 1468-1475$.

Smith CB, Betz WJ (1996) Simultaneous independent measurements of endocytosis and exocytosis. Nature 380:531-534.

Stevens CF, Sullivan JM (1998) Regulation of the readily releasable vesicle pool by protein kinase C. Neuron 21:885-893.

Tong G, Malenka RC, Nicoll RA (1996) Long-term potentiation in cultures of single hippocampal granule cells: a presynaptic form of plasticity. Neuron 16:1147-1157.

Trudeau LE, Doyle RT, Emery DG, Haydon PG (1996) Calciumindependent activation of the secretory apparatus by ruthenium red in hippocampal neurons: a new tool to assess modulation of presynaptic function. J Neurosci 16:46-54.

Vautrin J, Barker JL (1995) How can exocytosis account for the actual properties of miniature synaptic signals? Synapse 19:144-149.

Villacres EC, Wong ST, Chavkin C, Storm DR (1998) Type 1 adenylyl cyclase mutant mice have impaired mossy fiber long-term potentiation. J Neurosci 19:3186-3194.

Wall MJ, Usowicz MM (1998) Development of quantal properties of evoked and spontaneous synaptic currents at a brain synapse. Nat Neurosci 8:675-682.

Wang S, Prange O, Murphy TH (1999) Amplification of calcium signals at dendritic spines provides a method for CNS quantal analysis. Can J Physiol Pharmacol, in press.

Zucker RS (1996) Exocytosis: a molecular and physiological perspective. Neuron 17:1049-1055. 